\title{
Integrative Review: Evidences On The Practice Of Intermittent/ Indwelling Urinary Catheterization
}

\author{
Flávia Falci Ercole ${ }^{1}$ \\ Tamara Gonçalves Rezende Macieira² \\ Luísa Cristina Crespo Wenceslau² \\ Alessandra Rocha Martins ${ }^{2}$ \\ Camila Cláudia Campos² \\ Tânia Couto Machado Chianca ${ }^{3}$
}

Objective: to seek the best evidence available in the literature concerning the knowledge produced and related to the techniques of intermittent and indwelling urinary catheterization, so as to place the nursing care given to patients submitted to urinary catheterization on a scientific foundation and to prevent urinary tract infections. Method: the literature search was undertaken in the Pubmed and Cochrane databases for the development of the integrative review. The sample was of 34 articles. These were analyzed by two independent researchers using an instrument adapted for ascertaining the level of evidence and the grade of recommendation, in addition to the use of the Jadad scale. Results: the evidence available related to the nursing care for patients submitted to urinary catheterization is: the infection rate in the urinary tract does not alter whether the perineum is cleaned with sterile water or not, or with the use of povidone-iodine solution or chlorhexidine; or using clean or sterile technique. The use of an intermittent catheter with clean technique results in low rates of complications or infections compared to the use of an indwelling catheter. The removal of the catheter in up to 24 hours after surgery and the use of an antimicrobial-impregnated or hydrophilic-coated catheter reduce urinary tract infection. Conclusions: there are controversies in relation to periurethral cleansing technique, the type of material the catheter is made of, and some procedures for the maintenance and removal of the catheter. This review's results represent an updating of the nurse's conducts and decisionmaking for the prevention of urinary tract infections in urinary catheterization.

Descriptors: Urinary Catheterization; Urinary Tract Infections; Evidence-Based Nursing; Nursing.

\footnotetext{
${ }^{1}$ PhD, Adjunct Professor, Escola de Enfermagem, Universidade Federal de Minas Gerais, Belo Horizonte, MG, Brazil. 2 Undergraduate student in Nursing, Escola de Enfermagem, Universidade Federal de Minas Belo Horizonte, MG, Brazil. ${ }^{3}$ PhD, Full Professor, Escola de Enfermagem, Universidade Federal de Minas Gerais, Belo Horizonte, MG, Brazil.
} 


\section{Introduction}

Urinary catheterization is an invasive procedure in which a urethral catheter is inserted into the bladder with the aim, among others, of the draining of urine in patients with problems in eliminating urine. The drainage of urine may be undertaken using an open system (intermittent or for relief) or a closed one (indwelling) and through the supra-pubic route ${ }^{(1)}$.

Urinary Tract Infections (UTI) are responsible for over $30 \%$ of all Healthcare Associated Infections (HAI), being in their entirety related to the instrumentation of the urinary tract, the most important isolated risk factor and that which predisposes patients to infection ${ }^{(1)}$. Infection may arise in $1-2 \%$ of patients submitted to catheterization with an indwelling catheter ${ }^{(2-3)}$.

Due to the high incidence of UTI in the hospital setting, preventive measures must be adopted to reduce complications and treatment costs. In this perspective it is necessary that nursing actions based on clinical evidence should be used and updated so as to keep up with technological advances in health practices, to meet the increasingly participative and critical demand from health service users, and to ensure quality and safety in care.

Evidence-based health practice is characterized by the organization of information supported by scientifically-relevant results, identifying the most efficient and safest conducts for clinical problems in a specified client group(4). As a result of this conception, practice based in intuition, in non-systematized clinical experience, and in physio-pathological theories has been disregarded, giving way to the conscious and careful use of the best available evidence for taking decisions about patient care, minimizing complications and improving the care given.

Historically, nursing has been responsible for carrying out various technical procedures in health care, principally actions of promotion, treatment or rehabilitation, directed at a clientele with acute or chronic clinical problems. Among these, patients with alterations in urinary function and who need urinary catheterization represent about $10 \%$ of hospitalized patients $^{(1,3)}$.

It is known that catheterization with intermittent or indwelling catheters in the hospital setting is an aseptic technique ${ }^{(3)}$ which must be undertaken by a qualified and trained nurse or nurse technician, so as to minimize the complications inherent to the procedure, including $\mathrm{UTI}^{(1-3)}$.
In our professional experience and in line with the findings in the literature, it is observed that health professionals in different health institutions carry out the steps of the technique of the urinary catheter's insertion and maintenance in different ways. In relation particularly to periurethral cleansing with anti-septic and sterile solutions and the period of the removal of the catheter, among others, one can see disagreement regarding best practice.

It may be ascertained that there is no standardization or even consensus among professionals and institutions in relation to the stages of the procedure, despite some recommendations made with a view to preventing UTI having been published by the Center for Disease Control and Prevention (CDC) in the Guideline for Prevention of Catheter-Associated Urinary Tract Infections in 1981. It is worth noting that the most recent updating of this manual was in undertaken in 2008, published in 2009(1).

Urinary catheterization is an invasive procedure which nurses carry out as part of the routine of their care practice. Despite being considered a common procedure, it is associated with complications which require efforts from nursing to be controlled. Safe nursing care becomes essential, with quality and at a lower cost based on updated information. Currently, there is an absence of standardization of the urinary catheterization technique in different health institutions.

Thus, this study's objective was to seek out the best evidence available in the literature about the knowledge produced on the technique of urinary catheterization with intermittent or indwelling catheters, so as to provide a scientific basis for nursing care given to patients submitted to urinary catheterization, with a view to preventing UTI.

\section{Method}

An integrative review (IR) was undertaken, following the stages: selecting the issue in question (elaboration of the guiding question), establishing the inclusion and exclusion criteria for the articles, selecting the articles (sample selection), and analysis and interpretation of the results.

The initial survey of the indexed publications was undertaken between May and November 2010 in the U.S. National Library of Medicine National Institute of Health - PubMed and Cochrane Reviews databases, due to access to these being free of charge. For PubMed, the descriptors Urinary Catheterization and Urinary Tract Infections were used, without a limit on the 
period of publication, and for the Cochrane database, the descriptor Urinary Catheterization was used. In addition to the search in these databases, a reverse search was undertaken based on the articles found in the above databases, irrespective of the articles' year of publication.

Table 1 describes the path traced in the identification and selection of articles which made up the sample study.

Table 1 - Electronic search strategy in the databases, May to November 2010

\begin{tabular}{|c|c|c|c|c|}
\hline Data-base & Descriptors & $\begin{array}{c}\text { Articles found } \\
n\end{array}$ & $\begin{array}{c}\text { Articles selected } \\
\mathbf{n}\end{array}$ & $\begin{array}{c}\text { Sample } \\
\mathbf{n}\end{array}$ \\
\hline PubMed & Urinary Catheterization/Urinary Tract Infections & 445 & 99 & 20 \\
\hline Cochrane & Urinary Catheterization & 222 & 25 & 12 \\
\hline Total & & 667 & 124 & 32 \\
\hline
\end{tabular}

Note: The articles found and selected through the reverse search did not form part of the total of the articles found in the two data-bases.

After research in the data-bases, the following inclusion criteria were adopted for the selection of articles: articles with abstracts, complete and available in Portuguese, English and Spanish, and which addressed the issues of urinary catheterization and infection of the urinary tract, studies classified as Meta-analysis, Systematic Review (SR) and Randomized Clinical Trial (RCT), with levels of evidence 1 or 2 respectively(5), undertaken in human beings, without limitation of the period of publication.

As exclusion criteria, the authors chose nonrelevancy to the issue of urinary catheterization or UTI, as well as articles which dealt with the use of prophylactic use of antibiotics for the prevention of UTI, and suprapubic catheterization.

The selective reading of the 667 articles found on PubMed and Cochrane was carried out, initially, with analysis by title and abstract. The articles duplicated in both databases were counted only once. 99 studies were selected from PubMed based on the titles and abstracts. Following that, an integral and critical reading of the texts was done, resulting in the selection of 20 articles. Based on the search carried out in the Cochrane database, 25 articles were chosen after reading the titles and abstracts, which were then read in full. Of the articles, 12 were selected. Of the 124 articles selected in the two data-bases, 92 were excluded following application of the exclusion criteria pre-established for the study.

Using the reverse search, based on the reading of the 32 articles which made up the sample extracted from the two data-bases researched, 10 were found related to the issue, of which 08 were read in full; of these, 06 were excluded for not meeting the study's inclusion criteria. The study's final sample had 34 articles.

A data collection instrument was adapted and used for characterization of the selected studies ${ }^{(4-5)}$ containing items such as the descriptors used, title, authors, area of work, year of publication, language, design, objectives, method, results, conclusion, recommendations, limitations and level of scientific evidence, among others.

The articles selected were evaluated in relation to the level of evidence and grade of recommendation ${ }^{(5)}$. The Jadad scale ${ }^{(6)}$ was used for evaluating the methodological quality of the RCT selected in this study. This scale scores articles, from zero (0) to five (5), according to their methodological quality and detail. One point is attributed for each positive response related to three questions referred to the description of randomization, the method of blinding, and follow-up losses. A further point is attributed for each randomization and appropriate blinding, up to a maximum of five points. A score of over three points means a RCT has high methodological rigor, and under three constitutes poor methodological quality.

All the RCT were analyzed by two independent researchers. Each researcher scored the studies and the results obtained individually were later compared. The discrepancies in the scores were revised by another two researchers so that the doubts concerning classification might be eliminated.

The results extracted from the 34 articles which made up the sample were included in the study's results and discussion.

\section{Results}

This review's sample was made up of 34 studies, of which 33 (97\%) were published in English, 01 (3\%) in Spanish and none in Portuguese. All of the publications $(100 \%)$ are international and originate from countries such as India, Israel, Iran, Canada, Australia, Nigeria, the United States of America, China, France, Denmark, Sweden and others, predominantly English-speaking.

Of the review's 34 articles, 01 (3\%) was classified as Meta-analysis, 28 (75\%) were RCT and 08 (22\%) were Systematic Reviews. All the studies presented level 
of scientific evidence 1 or 2 .

Among the 28 RCT selected, 10 (36\%) received a Jadad Scale score below three, and 18 (64\%) articles obtained scores over three, presenting high methodological quality.

The articles were published between 1980 and 2010. Of the 34 articles, 25 (66\%) had been published in the previous five years. Five articles (13\%) were published between 2000 and 2003; three (8\%) had been published in the nineteen-eighties and five (13\%) in the nineteen-nineties.

Of the 34 articles used in the study, eight (23.5\%) were elaborated by researchers in the area of nursing; five $(10.5 \%)$ were developed in partnership with doctors; $19(55.8 \%)$ solely by doctors, one article $(3 \%)$ by doctors and others, and in the case of one of the articles
$(3 \%)$, it was not possible to identify the researchers' area of work.

Three subject areas were established to facilitate the presentation and organization of the results, as described below:

\section{Cleansing of the periurethral region}

This subject area was comprised of articles which dealt with the type of solution used, the cost of the procedure, the cleansing of the health professional's hands before the carrying out of the catheterization procedure, and the use of sterile technique, clean technique, intermittent self-catheterization and intermittent catheterization, and the relationship with the occurrence of UTI. (Table 2).

Table 2 - Description of studies included in the IR, according to the issue of periurethral cleansing

\begin{tabular}{|c|c|c|c|c|c|}
\hline Year & Author & Origin & Area/work & $\begin{array}{l}\text { Type of } \\
\text { study }\end{array}$ & $\begin{array}{c}\text { Evidence/ } \\
\text { Recommendation }\end{array}$ \\
\hline 2009 & Nasiriani et al. & Iran & Nursing & RCT & $2 \mathrm{~A}$ \\
\hline 2009 & Al-Farsi et al. & Canada & Medicine & RCT & $2 B$ \\
\hline 2008 & Cheung et al. & China & Nursing & $\mathrm{RCT}$ & $2 \mathrm{~B}$ \\
\hline 2006 & Turi et al. & Pakistan & Medicine & $\mathrm{RCT}$ & $2 \mathrm{~A}$ \\
\hline 2006 & Moore et al. & Canada & Nursing & $\mathrm{RCT}$ & $2 B$ \\
\hline 2005 & Lemke et al. & USA & Nursing & SR & $1 \mathrm{~B}$ \\
\hline 2001 & Webster et al. & Australia & Nursing & $\mathrm{RCT}$ & $2 \mathrm{~A}$ \\
\hline 2000 & Chan et al. & Hong Kong & Medicine & RCT & $2 \mathrm{~A}$ \\
\hline 1997 & Prieto et al. & USA & Nursing/Medicine & $\mathrm{RCT}$ & $2 \mathrm{~A}$ \\
\hline 1996 & Pickard et al. & UK & Nursing/Medicine & $\mathrm{RCT}$ & $2 \mathrm{~A}$ \\
\hline 1994 & Carapeti et al. & UK & Medicine & $\mathrm{RCT}$ & $2 \mathrm{~A}$ \\
\hline 1993 & Moore et al. & Canada & Nursing & $\mathrm{RCT}$ & $2 \mathrm{~A}$ \\
\hline 1980 & Harrison & USA & Medicine & RCT & $2 \mathrm{~A}$ \\
\hline 1985 & Cohen & USA & Medicine & $\mathrm{RCT}$ & $2 \mathrm{~A}$ \\
\hline
\end{tabular}

Studies which, prior to intermittent or indwelling catheterization, used for periurethral cleaning solutions with sterile water versus povidone-iodine 10\% (PVP-I); non-sterile water versus PVP-I; sterile water versus chlorhexidine $0.05 \%$; non-sterile water in comparison to chlorhexidine $0.1 \%$ to reduce UTI found an association between the groups in relation to UTI which was not statistically significant (7-10).

One study compared two techniques of cleansing of the hands of the professional who undertook the catheterization to verify the occurrence of UTI. No statistically-significant difference was found in the rates of UTI between the group in which the professional's hands were cleansed for 30 seconds and two pairs of gloves were worn, and the group in which the entire fore-arm was cleansed for three minutes and one pair of gloves was used(11).
To verify whether the incidence of UTI could be reduced by inverting the sequence of steps in the technique of urinary catheterization, it was determined that there was no statistically-significant difference in relation to bacteriuria and UTI when the stage of periurethral hygiene was carried out after the stage of insertion of the catheter ${ }^{(12)}$.

On comparing sterile technique to clean technique in 156 surgical patients who were submitted to indwelling catheterization in the pre-operative period, it was observed that there was no statistically-significant difference between the two groups in relation to the incidence of UTI, although there was a significant difference in relation to cost, with the sterile technique being twice as costly as the clean one ${ }^{(13)}$.

In patients with spinal cord injuries, carrying out clean, intermittent self-catheterization was associated 
with lower rates of UTI and complications of the lower urinary tract when compared to sterile indwelling catheterization(14-16). Patients with spinal cord injuries who were submitted to sterile intermittent catheterization presented a lower incidence of UTI when compared to the group with clean technique ${ }^{(17)}$.

Clean intermittent self-catheterization with use of sterile single-use catheter does not reduce the incidence of bacteriuria and UTI when compared to the use of the same catheter various times ${ }^{(18)}$.

A study undertaken evaluating the use of lubricating gel associated with an antiseptic (PVP-I) in clean intermittent self-catheterization demonstrated that it was more efficient than the use of common lubricating gel in the reduction of contamination of the bladder with micro-organisms ${ }^{(19-20)}$.

\section{Type of catheter material}

The articles which comprise this subject area deal with the type of material the catheters are made of and some substances for coating the intraluminal and external surfaces of the catheter and their relation to the reduction of infection of the urinary tract (Table 3 ).

Table 3 - Description of the studies included in the IR, according to the subject 'type of catheter material'.

\begin{tabular}{|c|c|c|c|c|c|}
\hline Year & Author & Origin & Area/work & Type of study & $\begin{array}{c}\text { Evidence/ } \\
\text { Recommendation }\end{array}$ \\
\hline 2008 & Schumm et al. & UK & Medicine and others & SR & $1 \mathrm{~B}$ \\
\hline 2007 & Stensballe et al. & Denmark & Medicine & RCT & $2 \mathrm{~A}$ \\
\hline 2007 & Jahn et al. & Germany & Nursing & SR & 1B \\
\hline 2007 & Moore et al. & Canada & Not identified & SR & $1 \mathrm{~B}$ \\
\hline 2005 & De Ridder et al. & Spain/Belgium & Medicine & $\mathrm{RCT}$ & $2 \mathrm{~A}$ \\
\hline 2003 & Vapnek et al. & USA & Medicine & $\mathrm{RCT}$ & $2 \mathrm{~A}$ \\
\hline 2000 & Thibon et al. & France & Medicine & RCT & $2 \mathrm{~B}$ \\
\hline 1990 & Liedberg et al. & Sweden & Medicine & $\mathrm{RCT}$ & $2 \mathrm{~A}$ \\
\hline 1986 & Klarskov et al. & Not identified & Medicine & RCT & $2 \mathrm{~B}$ \\
\hline
\end{tabular}

Hospitalized patients who use an indwelling catheter impregnated with silver oxide when compared to a common catheter (plastic, latex, silicone, silicone hydrogel, polyvinyl-PVC) for a short period of time did not have a statistically-significant reduction in bacteriuria and UTI. The use of catheters impregnated with silver alloy for up to one week when compared to common catheters had a significant reduction in the incidence of asymptomatic bacteriuria. With more than one week of catheterization, the risk of asymptomatic bacteriuria continued reduced with the use of a silver alloy coated catheter(21-22). A reduction in UTI was also obtained when a hydrophilic coated catheter, rather than a plastic one, was used in patients carrying out self-catheterization (23). The use of a hydrophilic coated catheter rather than a PVC one presented a lower rate of UTI, but the association was not significant ${ }^{(24)}$. The use of a hydrogel catheter combined with silver salts in comparison with a common catheter in patients needing catheterization for more than three days did not reduce the incidence of UTI(25).

The use of catheters impregnated with antibiotics for up to a week was effective in the reduction of bacteriuria, although this data was not very conclusive in confirming this same efficacy when the catheter was used for a prolonged period(21). When a catheter impregnated with nitrofurazone was used, in comparison with a silicone catheter, there was a reduction in the incidence of bacteriuria and funguria(26).

There is no evidence supporting the idea that the use of catheters coated with any sort of antiseptic or antimicrobial solution is more beneficial than the use of common catheters in reducing UTI in patients who need urinary catheterizing for prolonged periods(27). There is not enough evidence to determine which is the best type of urinary catheter, in terms of prevention of $\mathrm{UTI}^{(28-29)}$.

\section{Maintenance and removal of the catheter}

The articles comprising this subject area are about the length of time the catheter remains in situ and its removal, use of a fixation device and the procedure of clamping of the closed system and its relation to reduction of UTI (Table 4). 
Table 4 - Description of the studies included in the IR, according to the issue of maintenance and removal of the urinary catheter

\begin{tabular}{|c|c|c|c|c|c|}
\hline Year & Author & Origin & Area/work & Type of study & $\begin{array}{c}\text { Evidencel } \\
\text { Recommendation }\end{array}$ \\
\hline 2010 & Zmora et al. & Israel & Medicine & RCT & $2 \mathrm{~A}$ \\
\hline 2010 & Kamilya et al. & India & Medicine & RCT & $2 \mathrm{~A}$ \\
\hline 2009 & Zaouter et al. & Canada & Medicine & $\mathrm{RCT}$ & $2 \mathrm{~A}$ \\
\hline 2009 & Liang et al. & Taiwan & Nursing/Medicine & $\mathrm{RCT}$ & $2 \mathrm{~A}$ \\
\hline 2008 & Onile et al. & Nigeria & Medicine & RCT & $2 \mathrm{~A}$ \\
\hline 2008 & Joanna Briggs Institute & Australia & Nursing & $\mathrm{SR}$ & 1B \\
\hline 2008 & Tenke et al. & Asia and Europe & Medicine & Meta-analysis & $1 \mathrm{~A}$ \\
\hline 2008 & Sekhavat et al. & Iran & Medicine & $\mathrm{RCT}$ & $2 \mathrm{~A}$ \\
\hline 2008 & Loeb et al. & Canada & Nursing/Medicine & RCT & $2 \mathrm{~A}$ \\
\hline 2007 & Thakur et al. & Nepal & Medicine & RCT & $2 \mathrm{~A}$ \\
\hline 2006 & Darouiche et al. & USA & Nursing/Medicine & $\mathrm{RCT}$ & $2 \mathrm{~A}$ \\
\hline
\end{tabular}

In surgical patients, the removal of the indwelling catheter in the first day post-surgery, compared to removal on the fourth or fifth day postoperative was associated with a lower incidence of UTI, although there was an increased risk of re-catheterization(30-36).

A study of adult patients submitted to urological and gynecological surgery and who were submitted to indwelling urinary catheterization ascertained that the removal of the urinary catheter at midnight is recommended and that it is associated with a reduced hospital stay, with reduced need for re-catheterization and with lower costs. The late removal of the catheter (after 14 days) was related to an increased risk of UTI ${ }^{(37-38)}$.

There was no statistically-significant difference in the UTI rates for clamping a closed system for a determined period before removing it, compared to letting it drain urine freely for 24 or 72 hours before removing the catheter(37).

When a Statlock $₫$ brand fixation device for indwelling catheters was used in adult patients with spinal cord injury, a statistically-insignificant association with an increase in UTI rates and complications with lesion of the urethral meatus was verified. Further studies on this device need to be undertaken ${ }^{(39)}$.

The length of time the catheter remains in situ must be monitored in line with the patient's clinical conditions. The catheter must not be maintained in the patient without a carefully-taken clinical reason. This safe practice may avoid UTI and other complications ${ }^{(40)}$.

\section{Discussion}

Urinary tract infections (UTI) are among the most frequent complications related to the procedure of catheterization $^{(1)}$. Approximately $10 \%$ of hospitalized patients are submitted to urinary catheterization ${ }^{(2-3)}$.
Urinary catheterization is one of the nursing interventions established for treating acute and chronic pathologies which alter urinary elimination. It is a procedure widely used in care both in the hospital and home setting and must be free of risks, preserving patient safety and maintaining the quality of the service provided.

In spite of the risks posed by the insertion of a catheter through the urinary tract already being known, and despite the registered nurse and the licensed professional nurse being the professionals who are responsible for carrying out the procedure, one may observe that clinical research undertaken by nurses on this subject remains incipient. Of the 34 articles which made up this review, only eight $(23.5 \%)$ were produced by nurses, showing that clinical research carried out by these professionals is necessary, principally in relation to the type of catheterization, some solutions for periurethral cleansing, and maintenance and removal of the catheter.

The few studies found have searched for clinical evidence about the effectiveness of the nursing interventions in the reduction of the risks of UTI and the complications related to the use of catheters. It was observed that there is no consensus in the various aspects of the technique of urinary catheterization in relation to: the cleansing of the periurethral area with antiseptics, sterile water or tap water; recommendation for sterile and non-sterile technique; type of catheter material; and the maintenance, length of time in situ and catheter removal.

It was observed that use of anti-septic solution during nursing care for the catheterized patient does not reduce the risk of developing a UTI, suggesting that cleaning of the periurethral area prior to insertion of 
the catheter should be undertaken, but that this can be done with non-sterile water - the economical alternative - sterile water, or antiseptic solution (chlorhexidine and PVP-I) - all being equally effective ${ }^{(7-10)}$. Some of these findings in relation to the development of UTI and costs need to be confirmed.

Studies were not found in this IR dealing with cleansing of the perineum with soap and water in the hospital setting, or dealing with the use of sterile saline solution for washing the antiseptic solution from the mucosa. It is known that these solutions are part of the care protocols in different institutions, without studies having been conducted to verify their association with the development of UTI and the procedure's costs.

Regarding the type of catheterization, studies have compared clean intermittent catheterization with clean intermittent self-catheterization and indwelling catheterization, and the clean technique with the sterile technique in relation to UTI. Clean intermittent catheterization is a safer procedure and has a lower rate of complications and infections when compared to indwelling catheterization ${ }^{(13-16)}$. It is known that the indwelling catheter is more prone to the development of UTI, and because of this it is recommended that its insertion should be carried out under aseptic conditions and that it should be kept closed to avoid infection. Inconclusive results were obtained in comparing intermittent catheterization with indwelling catheterization in relation to reduction of bacteriuria and $\mathrm{UTI}^{(17)}$.

In the home setting, clean intermittent selfcatheterization is related to reduction in UTI and bacteriuria(14). Intermittent self-catheterization with a sterile single-use catheter, compared to a non-sterile re-usable catheter, did not reduce the incidence of bacteriuria(18).

The insertion of the catheter using the sterile technique, compared to the clean technique, suggests a relation with the reduction of $\mathrm{UTI}^{(17)}$. In contrast, another two studies did not observe reduction in UTI with the use of the sterile technique(13,15). It should be noted that in these three, methodologically well-conducted, studies, the results found were contradictory, which shows the need for further research to evaluate the risk of UTI.

The majority of the studies related to the catheter material points to a reduction in UTI when silver alloy coated catheter and those impregnated with antibiotic are used for a period of up to one week, in comparison with catheters made from silicone, silicone with hydrogel, latex and PVC(21-22). Catheters coated with silver alloy, when compared with those of silicone and latex, reduce bacteriuria and UTI, even when the length of time the catheter remains in situ is prolonged ${ }^{(22)}$. The rate of UTI was significantly lower in the group of patients who used catheters with hydrophilic coatings in comparison with those of PVC(23-24). There is insufficient evidence to conclude that the use of hydrogel catheters and silver salts can reduce UTI ${ }^{(25)}$. There is no evidence to justify the advantage of catheters coated with substances over common catheters in relation to UTI ${ }^{(27-29)}$. Studies must be undertaken to evaluate the cost-benefit ratio for the use of these catheters for any type of patient.

The recommendation for use of a urinary catheter must be made carefully in accordance with the clinical needs presented by the patient. The use of the urinary catheter in abdominal and pelvic surgery in which epidural anesthetic was used is recommended with the aim of preventing complications such as urinary retention, until the physiological functions of urinary elimination are re-established. The safe use of the urinary catheter reduces its length of time in situ, but does not point to a reduction in $\mathrm{UTI}^{(39)}$.

It is recommended that catheter remain in place after surgery for up to 24 hours, to reduce rates of symptomatic UTI ${ }^{(30-33,35-37)}$. It is suggested that the early removal of the catheter, on the other hand, during the night in comparison to the morning, decreases the patient's stay in hospital, saving resources ${ }^{(37)}$. There was neither suggestive nor conclusive evidence regarding the best period of the day for removing the catheter, in relation to reducing $\mathrm{UTI}^{(37)}$. Further studies must be carried out for a secure recommendation concerning the best period of the day to remove urinary catheters.

The use of lubricating gel with PVP-I to facilitate the insertion of the urinary catheter was demonstrated to be efficient in reducing contamination of the bladder with microorganisms during self-catheterization and in intermittent catheterization performed by family members and caregivers in the home ${ }^{(19-20)}$. Studies in the hospital setting must be undertaken to establish the efficacy of using lubricating gel with PVP-I, normal lubricating gel, and sterile gel in relation to UTI and the procedure's costs.

The type of fixation of the catheter seems not to influence the rate of symptomatic UTI. A randomized clinical trial comparing the Statlock catheter's fixation device with pre-existing methods such as tape, velcro, Cathsecure or no type of fixation found a reduction of $45 \%$ in symptomatic UTI, although there was no statistically-significant association between the use of 
the device and $\mathrm{UTI}^{(40)}$. This article's Jadad classification below three - demonstrates the need for further studies on this subject.

There is limited evidence regarding the practice of clamping the catheter before removing it to reduce UTI, although one study recommends that if clamping should be done, it should be done for a determined period before the removal, when compared to free drainage of urine during 24 or 72 hours before the catheter's removal(37).

\section{Conclusion}

Urinary catheterization is a widely-practiced procedure, which benefits the patient in various clinical situations, despite the complications which are inherent to its use. The role of the nurse and the health team in preventing the complications, principally UTI, is essential. These professionals must adopt evidencebased guidelines to ensure the quality of the care and minimize the occurrence of complications such as UTI.

The evidence found in this study, according to level and degree of recommendation, were:

- periurethral cleansing done with tap water, sterile water, antiseptic solution (chlorhexidine and PVP-I) were not statistically associated with UTI (2A and $2 \mathrm{~B}$ );

- clean, intermittent catheterization is the safest procedure and has the lowest rate of complications and of UTI, when compared with indwelling catheterization (2A).

- clean intermittent self-catheterization was associated with lower rates of UTI and complications of the lower urinary tract when compared to sterile indwelling catheterization ( $2 \mathrm{~A}, 2 \mathrm{~B}$ and $1 \mathrm{~B})$. A lower incidence of UTI was found when sterile intermittent catheterization was carried out as against the clean technique. (2A);

- the clean technique may be used as an alternative to the sterile technique in intermittent self-catheterization in the home $(2 \mathrm{~A})$;

- single use of the sterile catheter in intermittent self-catheterization does not reduce the incidence of bacteriuria and UTI when compared to the use of a clean catheter for repeated catheterizations (2A).

- catheters coated with silver alloy and antibiotic, when used for a period of up to one week, in comparison with common catheters (silicone, silicone with hydrogel, latex and PVC) reduce bacteriuria and UTI (2A, 1B); catheters coated with silver alloy reduce bacteriuria and UTI even when the catheter remains in situ for a prolonged period ( $2 \mathrm{~A})$;

- there is insufficient evidence to determine which is the best type of urinary catheter with a view to the prevention of UTI $(2 B, 1 B)$, principally the ones coated with some type of antiseptic or antimicrobial solution in relation to UTI in patients who need prolonged urinary catheterization (1B);

- the hydrophilic coated catheter, when compared to the one made of plastic, reduced UTI in self-catheterization $(2 \mathrm{~A})$; the hydrophilic coated catheter, when compared to the PVC one, presented a lower rate of UTI, but this association was not significant (2A); the hydrogel coated catheter, combined with silver salts, in comparison with the common catheter in patients needing catheterization for more than three days did not reduce the incidence of UTI (2B);

- the use of lubricating gel with PVP-I reduced the contamination of the bladder with micro-organisms during self-catheterization and in intermittent catheterization carried out by family members and caregivers in the home $(2 \mathrm{~A})$;

- it is recommended that indwelling catheters remain in place for 24 hours following surgery so as to reduce rates of symptomatic UTI and other complications (2A, 1B);

- the early removal of indwelling catheters in surgical patients is associated with a reduction in risk of UTI and shorter stays in hospital, but also with an increased risk of urinary retention $(2 A, 1 B)$; removal at midnight is recommended in patients submitted to urological and gynecological surgery (1B);

- the fixation of the catheter with a Startlock device, compared to common methods (tape, velcro, CathSecure or no type of fixation) reduced symptomatic UTI by $45 \%$, although there was no statistically significant association between the use of the device and the UTI (2A);

- there was no statistically significant difference in the rates of UTI on clamping the closed system for a specified period before removal, when compared to free drainage of urine for 24 or 72 hours before the catheter's removal (1B).

- the safe use of the urinary catheter reduces the time it remains in place but does not point to reduction in UTI (2A).

The literature found on the issue in this review does not include all the nursing interventions which may be related to the risks presented by patients using urinary catheters. Some studies which evaluated the same evidence present opposing results. In this regard, it is recommended that clinical studies be conducted in hospitals with different populations, to establish the best nursing care for patients submitted to urinary catheterization, particularly nursing care related to 
solutions used in cleansing of the perineum, sterile and non-sterile technique, the period of the day for removing the catheter, the use of clamping for catheter removal, and the cost effectiveness of the catheter material.

\section{References}

1. Gould CV, Umscheid CA, Agarwal RK, Kuntz G, Pegues DA, Health Care Infection Control Practices Advisory Committeel. Guideline for prevention of catheterassociated urinary tract infections 2009. Atlanta, GA: Healthcare Infection Control Practices Advisory Committee; 2009. 67 p.

2. Souza-Neto JL, Oliveira FV, Kobaz AK, Silva MNP, Lima $A R$, Maciel LC. Infecção do trato urinário relacionada com a utilização do cateter urinário de demora: resultados da bacteriúria e da microbiota estudadas. Rev Col Bras Cir. 2008;35(1):28-33.

3. Queirós MI, Cipriano MAB, Santos MCL, Cardoso MVML. Infecções urinárias e uso de cateter vesical de demora em unidade pediátrica. Rev Rene. 2011;12(2):295-301. 4. Soares BGO, autor. Prática de enfermagem baseada em evidências. In: Bork AMT. Enfermagem Baseada em Evidências. Rio de Janeiro: Guanabara Koogan; 2005. p. 3-13

5. Phillips B, Ball C, Sackett D, Badenoch, Straus S, Haynes B, Dawes M. Levels of Evidence and Grades of Recommendation. 1998; [acesso 13 jan 2005]; Oxford: Oxford Centre for Evidence-Based Medicine - Centre for Evidence-based Medicine; 2005. Disponível em: http: // www.cebm.net/.

6. Jadad A, Moore RA, Carroll D, Jenkinson C, Reynolds DJM, Gavaghan DJ, McQuay HJ. Assessing the quality of reports of randomized clinical Trial: Is blinding necessary? Control Clin Trials. 1996;17(1):1-12.

7. Nasiriani K, Kalani Z, Farnia F, Motavasslian M, Nasiriani F, Engberg $S$. Comparison of the effect of water vs. povidone-iodine solution for periurethral cleaning in women requiring an indwelling catheter prior to gynecologic surgery. Urol Nurs. 2009; MarApr;29(2):118-21, 131.

8. Al-Farsi S, Oliva M, Davidson R, Richardson SE, Ratnapalan S. Periurethral cleaning prior to urinary catheterization in children: sterile water versus $10 \%$ povidone-iodine. Clin Pediatr (Phila). 2009;48(6):65660. Epub 2009 Mar 4.

9. Cheung K, Leung P, Wong YC, To OK, Yeung YF, Chan MW, et al.. Water versus antiseptic periurethral cleansing before catheterization among home care patients: a randomized controlled trial. Am J Infect
Control. 2008;36(5):375-80.

10. Webster J, Hood RH, Burridge CA, Doidge ML, Phillips KM, George N. Water or antiseptic for periurethral cleaning before urinary catheterization: a randomized controlled trial. Am J Infect Control. 2001;29(6):389-94. 11. Pickard WG, Grundy DJ. A comparison of two methods of sterile urethral catheterisation in spinal cord injured adults. Paraplegia. 1996;34(1):30-3.

12. Chan YM, Ngai SW, Hon E, So WK. Could the incidence of postoperative urinary tract infection be reduced by reversing the sequence of vaginal cleansing and urethral catheterization? J Hosp Infect. 2000;46(1):67-72.

13. Carapeti EA, Andrews SM, Bentley PG. Randomised study of sterile versus non-sterile urethral catheterisation. Ann R Coll Surg Engl. 1996;78(1):59-60.

14. Turi MH, Hanif S, Fasih Q, Shaikh MA. Proportion of complications in patients practicing clean intermittent self-catheterization (CISC) vs indwelling catheter. J Pak Med Assoc. 2006;56(9):401-4.

15. Moore KN, Burt J, Voaklander DC. Intermittent catheterization in the rehabilitation setting: a comparison of clean and sterile technique. Clin Rehabil. $2006 ; 20(6): 461-8$.

16. Lemke JR, Kasprowicz K, Worral PS. Intermittent Catheterization for Patients With a Neurogenic Bladder: Sterile Versus Clean: Using Evidence-based Practice at the Staff Nurse Level J Nurs Care Qual. 2005;20(4):302-6.

17. Prieto-Fingerhut T, Banovac K, Lynne CM. A study comparing sterile and nonsterile urethral catheterization in patients with spinal cord injury. Rehabil Nurs. 1997;22(6):299-302.

18. Moore KN, Kelm M, Sinclair O, Cadrain G. Bacteriuria in intermittent catheterization users: the effect of sterile versus clean reused catheters. Rehabil Nurs. 1993;18(5):306-9.

19. Harrison LH. Comparison of a microbicidal povidoneiodine gel and a placebo gel as catheter lubricants. J Urol. 1980;124(3):347-9.

20. Cohen A. A microbiological comparison of a povidone-iodine lubricating gel and a control as catheter lubricants. J Hosp Infect. 1985; 6, SupplA:155-61.

21. Schumm K, Lam TB. Types of urethral catheters for management of short-term voiding problems in hospitalised adults. Cochrane Database Syst Rev. 2008;16(2):CD004013. 22. Liedberg H, Lundeberg T. Silver alloy coated catheters reduce catheter-associated bacteriuria. Br J Urol. 1990;65(4):379-81.

23. Vapnek JM, Maynard FM, Kim J. A prospective randomized trial of the LoFric hydrophilic coated catheter versus conventional plastic catheter for clean intermittent 
catheterization. J Urol. 200;3 Mar;169(3):994-8.

24. De Ridder DJ, Everaert K, Fernández LG, Valero $J \mathrm{~V}$, Durán $A B$, Abrisqueta $M L$, et al.. Intermittent catheterisation with hydrophilic-coated catheters (SpeediCath) reduces the risk of clinical urinary tract infection in spinal cord injured patients: a prospective randomised parallel comparative trial. Eur Urol. 2005;48(6):991-5. Epub 2005 Aug 15.

25. Thibon $P$, Le Coutour $X$, Leroyer R, Fabry J. Randomized multi-centre trial of the effects of a catheter coated with hydrogel and silver salts on the incidence of hospital-acquired urinary tract infections. J Hosp Infect. 2000;45(2):117-24.

26. Stensballe J, Tvede M, Looms D, Lippert FK, Dahl $B$, Tønnesen $E$, et al.. Infection risk with nitrofurazoneimpregnated urinary catheters in trauma patients: a randomized trial. Ann Intern Med. 2007; Sep 4;147(5):285-93.

27. Moore KN, Fader M, Getliffe K. Long-term bladder management by intermittent catheterisation in adults and children. Cochrane Database Syst Rev. 2007;17(4):CD006008.

28. Jahn P, Preuss M, Kernig A, Seifert-Hühmer A, Langer G. Types of indwelling urinary catheters for long-term bladder drainage in adults. Cochrane Database Syst Rev. 2007; 18(3):CD004997.

29. Klarskov P, Bischoff N, Bremmelgaard A, Hald T. Catheter-associated bacteriuria. A controlled trial with the Bardex Urinary Drainage System. Acta Obstet Gynecol Scand. 1986; 65(4):295-9.

30. Kamilya G, Seal SL, Mukherji J, Bhattacharyya SK, Hazra A. A randomized controlled trial comparing short versus long-term catheterization after uncomplicated vaginal prolapse surgery.J Obstet Gynaecol Res. 2010;36(1):154-8.

31. Zmora O, Madbouly K, Tulchinsky $H$, Hussein A, Khaikin M. Urinary bladder catheter drainage following pelvic surgery--is it necessary for that long? Dis Colon Rectum. 2010;53(3):321-6.

32. Zaouter C, Kaneva P, Carli F. Less urinary tract infection by earlier removal of bladder catheter in surgical patients receiving thoracic epidural analgesia. Reg Anesth Pain Med. 2009;34(6):542-8.

33. Liang $\mathrm{CC}$, Lee $\mathrm{CL}$, Chang $\mathrm{TC}$, Chang $\mathrm{YL}$, Wang $\mathrm{CJ}$, Soong YK. Postoperative urinary outcomes in catheterized and non-catheterized patients undergoing laparoscopic-assisted vaginal hysterectomy--a randomized controlled trial. Int Urogynecol J Pelvic Floor Dysfunct. 2009;20(3):295-300. Epub 2008 Nov 14.

34. Takur N, Gurung G, Rana A. A randomized controlled trial comparing short-term versus long-term catheterization after vaginal prolapsed surgery. $\mathrm{N}$ J Obstet Gynaecol. 2007; 2(1):29-34.

35. Onile TG, Kuti O, Orji EO, Ogunniyi SO. A prospective randomized clinical trial of urethral catheter removal following elective cesarean delivery. Int J Gynaecol Obstet. 2008;102(3):267-70. Epub 2008 Jul 7.

36. Sekhavat L, Farajkhoda T, Davar R. The effect of early removal of indwelling urinary catheter on postoperative urinary complications in anterior colporrhaphy surgery. Aust N Z J Obstet Gynaecol. 2008;48(3):348-52.

37. Joana Briggs Institute. Removal of shortterm indwelling urethral catheters. Nurs Stand. 2008;22(22):42-45.

38. Tenke $P$, Kovacs $B$, Bjerklund Johansen $T E$, Matsumoto T, Tambyah PA, et al.. European and Asian guidelines on management and prevention of catheterassociated urinary tract infections. Int J Antimicrob Agents. 2008;31 Suppl 1:S68-78. Epub 2007 Nov 14.

39. Loeb M, Hunt D, O'Halloran K, Carusone SC, Dafoe N, Walter SD. Stop orders to reduce inappropriate urinary catheterization in hospitalized patients: a randomized controlled trial. J Gen Intern Med. 2008;23(6):816-20. Epub 2008 Apr 18.

40. Darouiche RO, Goetz L, Kaldis T, Cerra-Stewart C, AISharif A, Priebe M. Impact of StatLock securing device on symptomatic catheter-related urinary tract infection: a prospective, randomized, multicenter clinical trial. Am J Infect Control. 2006;34(9):555-60. 